\title{
Pneumatocele complicated with bronchopleural fistula and pneumothorax in SARS-CoV2 pneumonia
}

\author{
Sofía Irigoyen*, Beatriz Esnaola, Karmelo Intxaurraga y Sorkunde Telletxea \\ Anesthesiology, Resuscitation and Pain Treatment Service, Hospital de Galdakao-Usansolo, Biscay, Spain
}

\begin{abstract}
Pulmonary pneumatoceles are acquired, air-containing cystic lesions that may develop as a complication of bacterial pneumonia, especially after staphylococcal pneumonia in pediatric patients. However, they are very rarely observed in adults. Less frequently, pneumatoceles may occur in association with other types of pneumonias or have a non-infectious etiology, such as thoracic surgery or mechanical ventilation, among others. In this article, we report a case of a 62-year-old male who developed multiple post-infectious pulmonary pneumatoceles complicated with bronchopleural fistula and hydropneumothorax, secondary to severe acute respiratory syndrome coronavirus 2 pneumonia with bacterial superinfection by Pseudomonas aeruginosa. The patient's clinical and radiological course improved after the percutaneous insertion of a chest tube, with complete resolution of the pneumatoceles and its complications.
\end{abstract}

Key words: Pneumatocele. Pneumonia. Bronchopleural fistula. Pneumothorax. Pseudomonas aeruginosa. COVID-19.

\section{Neumatocele complicado con fístula broncopleural y neumotórax en neumonía por SARS-CoV2}

\section{Resumen}

Los neumatoceles pulmonares son lesiones quísticas adquiridas de contenido aéreo que pueden desarrollarse como complicación de una neumonía bacteriana, en particular la neumonía estafilocócica en pacientes pediátricos. Es raro que aparezcan en adultos. Menos a menudo, pueden aparecer en neumonías de otras causas o relacionarse con causas no infecciosas, como la cirugía torácica o la ventilación mecánica, entre otras. En este artículo se presenta el caso de un varón de 62 años que desarrolló varios neumatoceles pulmonares posinfecciosos complicados con fístula broncopleural e hidroneumotórax, en relación con una neumonía viral por SARS-CoV-2 con sobreinfección bacteriana por Pseudomonas aeruginosa. La evolución fue favorable, clínica y radiológicamente, tras la colocación de un drenaje pleural percutáneo, con la resolución completa de los neumatoceles y sus complicaciones.

Palabras clave: Neumatocele. Neumonía. Fístula broncopleural. Neumotórax. Pseudomonas aeruginosa. COVID-19

Correspondence:

*Sofía Irigoyen

E-mail: sirigoyenmiro@gmail.com
Date of reception: 26-04-2021

Date of acceptance: 13-05-2021

DOI: 10.24875/RAA.21000001
Available online: 19-07-2021

Rev Argent Anestesiol. 2020;78:4-8 www.revistaargentinaanestesiologia.com open access article under the CC BY-NC-ND (http://creativecommons.org/licenses/by-nc-nd/4.0/). 


\section{Introduction}

Pulmonary pneumatoceles are thin-walled cystic lesions within the lung. They are commonly seen as a post-infectious complication of staphylococcal pneumonia in infants and young children. However, pneumatoceles are very unusual in adults with pneumonia or in association with viral pneumonia. The purpose of this article is to describe a case of an adult patient that developed multiple pneumatoceles that were probably post-infectious, as a result of secondary to severe acute respiratory syndrome coronavirus 2 (SARSCoV-2) viral pneumonia with bacterial superinfection by Pseudomonas aeruginosa.

\section{Case report}

We present a case of a 62-year-old male, without any known drug allergies or toxic habits. The patient's medical history included arterial hypertension in treatment with enalapril, without any other cardiovascular risk factors or known cardiopathy nor bronchopathy. He also presented eosinophilic esophagitis and lumbar disc herniation.

He was admitted in the emergency room referring physical discomfort, myalgia, and fever of $39^{\circ} \mathrm{C}$ for 3 days. He also presented with irritative cough and moderate dyspnea. He was initially admitted in the pneumology ward with the diagnosis of SARS-CoV-2 bilateral pneumonia. During the first $24 \mathrm{~h}$, he presented a clinical, radiological, and analytic worsening, presenting an acute respiratory failure in spite of $100 \% \mathrm{FiO}_{2}$, and a clinical course compatible with acute distress syndrome. Once he was admitted in the ICU, he was intubated and connected to mechanical ventilation, and was sedated with propofol, midazolam, and morphine.

During the $1^{\text {st }}$ days, the patient was hemodynamically stable with low doses of norepinephrine in relation with the use of sedation drugs. He also presented an acute renal failure that was solved within the first few days. Following the COVID-19 hospital protocol, he received treatment with hydroxychloroquine (200 mg every $12 \mathrm{~h}$ during 14 days), tocilizumab (two doses of $600 \mathrm{mg}$ and $400 \mathrm{mg}$, respectively), anakinra (200 $\mathrm{mg}$ the $1^{\text {st }}$ day and $100 \mathrm{mg}$ during the next 2 days), and metilprednisolone (80 $\mathrm{mg}$ the $1^{\text {st }}$ day, following a descending doses during 5 days).

He remained intubated and connected to mechanical ventilation during a total of 25 days, with the need of neuromuscular blockade initially and several cycles of prone position. Lung protective ventilation strategies were used

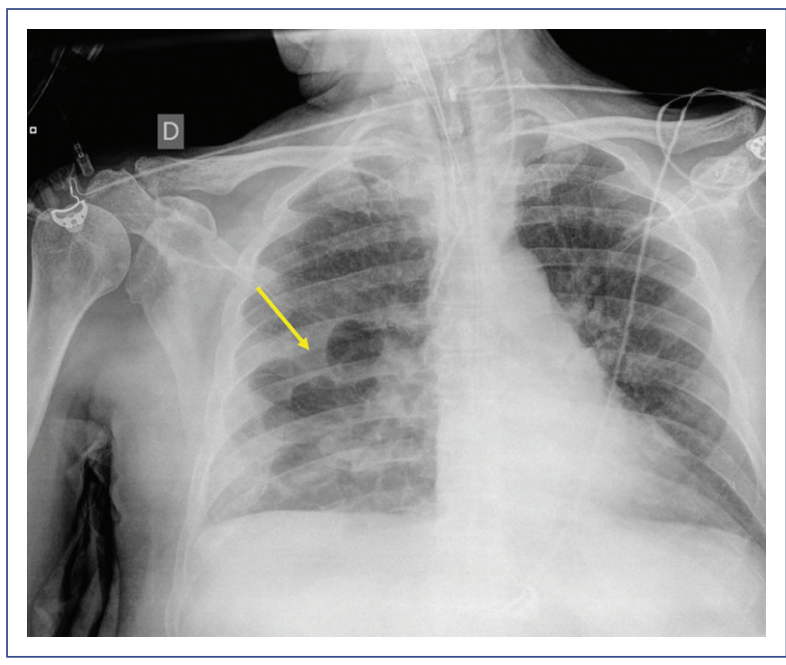

Figure 1. Anteroposterior chest X-ray with multiple welldefined radiolucent nodular images on the right hemithorax, suggestive of post-infectious pneumatoceles and bilateral alveolar and interstitial opacities.

at all times. Moreover, he presented a pulmonary bacterial superinfection, and endotracheal aspirates grew $P$. aeruginosa that was resistant to carbapenems and quinolones. Blood and urine cultures were negative. He received antibiotic treatment with piperacillin-tazobactam and amikacin, with good response.

It should be noted that extubation was attempted in two occasions, and in both cases, premature reintubation took place because of inadequate ventilatory mechanics and management of respiratory secretions. This was probably in relation to the severe myopathy and sarcopenia that the patient presented. Once he was successfully extubated and presented respiratory stability, he was transferred to the pneumology ward.

Within the first few days of hospitalization, the bilateral condensations on the chest radiography presented a progressive improvement, radiologically speaking. However, after 2 weeks, the right pleural effusion and multiple well-defined radiolucent nodular images appeared on a routine control chest radiography on the right hemithorax, which were suggestive of post-infectious pneumatoceles (Fig. 1). Due to the persistence of these images on radiographic controls that were made on the following days, a thoracic CT scan was made, which revealed multiple pneumatoceles, a loculated hydropneumothorax and a bronchopleural fistula (Fig. 2).

For this reason, a pleural chest tube for drainage was placed under ultrasound guidance, which was connected to high aspiration progressively until a maximum of 


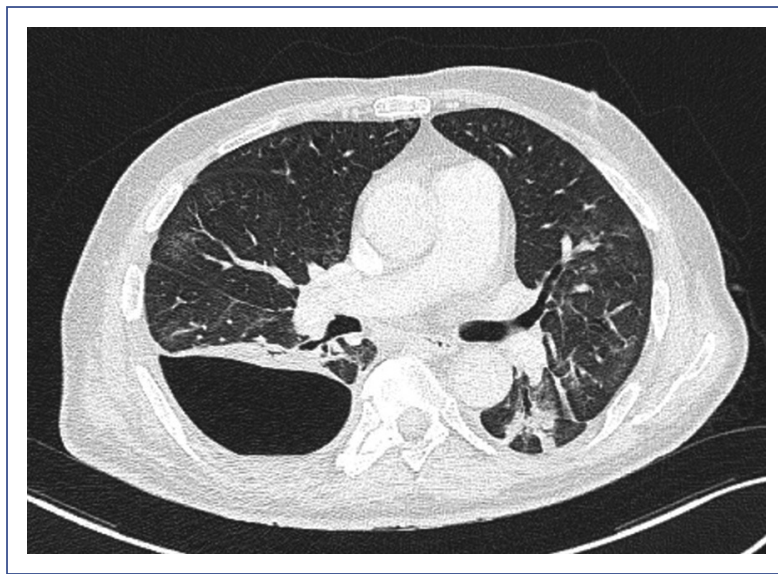

Figure 2. Thoracic computed tomography scan with the right posterior hydropneumothorax secondary to bronchopleural fistula.

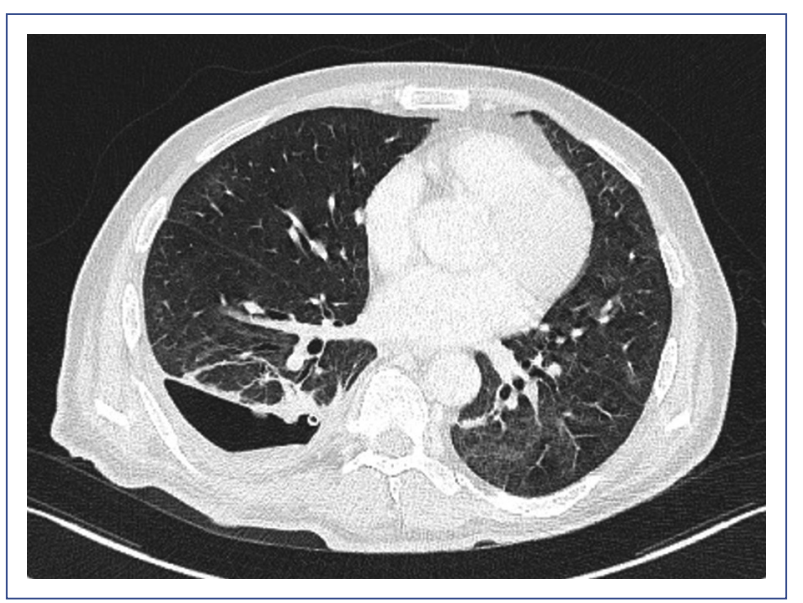

Figure 3. Thoracic computed tomography scan with the right posterior hydropneumothorax secondary to bronchopleural fistula reduced in size after a chest tube placement.

$-45 \mathrm{cmH}_{2} \mathrm{O}$. With this treatment, our patient experienced a significant clinical and radiological improvement, with complete resolution of the pneumatoceles and its complications over the next 15 days. Therefore, it was possible to remove the chest tube and after doing so, there was no evidence of reappearance of the pneumatoceles or the pneumothorax on the computed tomography (CT) scan that was done a few days later (Figs. 3 and 4). Moreover, the radiological course of the pneumonia was also satisfactory, with no signs of pulmonary fibrosis.

Due to the patient's improvement, both clinically and radiologically speaking, he was discharged from hospital after 2 months of hospitalization.

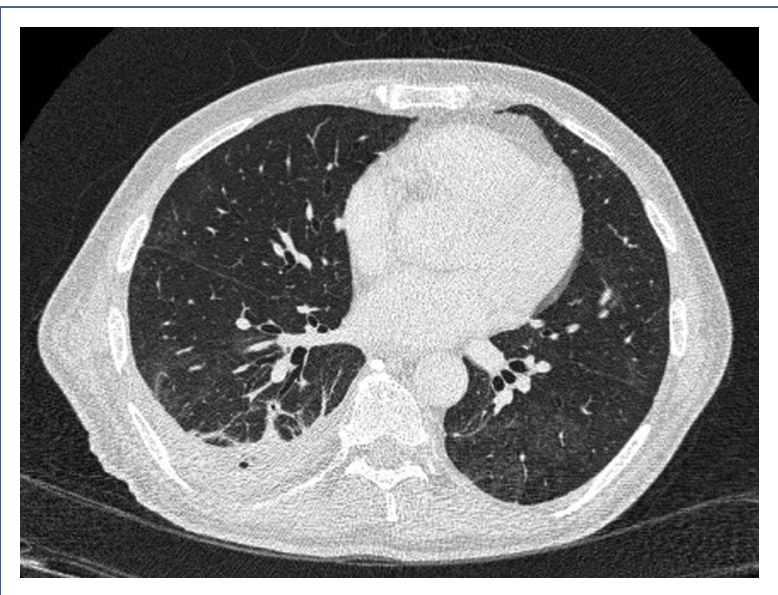

Figure 4. Thoracic computed tomography scan that shows significant radiological improvement of the right hydropneumothorax after the chest tube was removed.

\section{Discussion}

Pulmonary pneumatoceles, also known as pseudocysts, are acquired air-filled thin-walled cystic lesions that are formed in the lung parenchyma. They can be single lesions, but are more often multiple, like in our case. Size can vary from $>1 \mathrm{~cm}$ to occupying an entire hemithorax, with uniform thin walls that are less that $4 \mathrm{~mm}$. Apart from air, pneumatoceles may contain air-fluid levels. They can occur anywhere in the thoracic cavity, but lung apices are rare locations.

Pneumatocele formation has been described as a complication that may appear in association with pulmonary infections, especially bacterial pneumonias. They are commonly seen as a complication of staphylococcal pneumonia in infants and young children, but they are very rarely observed in adults ${ }^{1-3}$. In fact, almost $70 \%$ of the cases of pneumatoceles occur in pediatric patients, and Staphylococcus spp. is the most common causal agent ${ }^{4}$. Although they are less frequent, other causal agents have been described: Streptococcus pneumoniae, Haemophilus influenzae, Escherichia coli, Klebsiella pneumoniae, Pneumocystis jiroveci, and adenovirus y M. tuberculosis ${ }^{1,2,4-6}$. The etiology can also be non-infectious, and they may also develop secondary to thoracic trauma, thoracic surgery, or positive pressure mechanical ventilation ${ }^{3,4}$.

In our case, the etiology seems to be multifactorial. On the one hand, the most likely possibility seems to be a post-infectious complication after a viral pneumonia with bacterial superinfection by $P$. aeruginosa. It should be noted that the association of SARS-CoV-2 
virus with pneumatocele formation has not been described in literature yet and that pneumatoceles rarely develop in viral pneumonias. Taking this into account, it could be said that the appearance of pneumatoceles in our case seems more likely to be related to the bacterial superinfection. On the other hand, our patient was connected to mechanical ventilation for a long time, which may have been one of the triggering causes in spite of using protective mechanical ventilation at all times. Mechanical ventilation could have been the initial cause or could have contributed to its development and progression overtime. Finally, it should also be taken into account that our patient was immunosuppressed due to the therapies against COVID-19, with high doses of corticosteroid therapy during the $1^{\text {st }}$ days and other immunomodulatory drugs. Immunosuppression induced by these treatments can increase the risk of infections and its complications, like the appearance of pneumatoceles as a complication of pneumonia. This association has been previously described in literature, like the case of a patient who developed pneumatoceles as a complication of $E$. coli pneumonia in association with immunosuppression induced by long-term corticosteroid therapy because of an ankylosing spondylitis?.

The exact mechanism responsible for pneumatocele formation is unknown, but several theories have been proposed. According to the most accepted hypothesis, overdistension and localized alveolar necrosis is generated due to the bronchiolar obstruction that occurs secondary to the airway inflammation and edema. This leads to air trapping because of a "unidirectional valve mechanism," which allows the air to enter the cystic space but not to leave it ${ }^{1,4,6,8,9}$.

A chest X-ray may be useful for de initial diagnosis, but a CT scan gives the definitive diagnosis and is the gold standard in these cases, since it is the most accurate imaging technique and has the highest sensitivity for pneumatocele identification ${ }^{5,10}$. Moreover, it is also useful for the evaluation of its size, location, and the identification of complications.

Although pneumatoceles are usually asymptomatic and resolve spontaneously, complications may appear in some cases $^{10}$. Among the possible complications, pneumothorax and bronchopleural fistula secondary to the pneumatocele rupture are the most common, especially in patients undergoing mechanical ventilation ${ }^{1,3,4}$. Other possible complications are superinfection with the development of empyema and/or pulmonary abscess, significant pulmonary atelectasis, or tension pneumatocele with cardiorespiratory instability by compression of contiguous structures, among others ${ }^{1,3}$.

In most cases, pneumatoceles usually appear within the first 2 weeks of pneumonia infection and resolve spontaneously and completely within a few weeks to 6-12 months, especially in children ${ }^{2,4,5}$. However, in some cases, more invasive procedures may be needed, usually a percutaneous placement of a catheter drainage or a chest tube ${ }^{1,10}$, which is connected to negative aspiration until its resolution, like it occurred in the case of our patient.

Typically, invasive procedures are reserved for cases of large pneumatocele (when they occupy more than $50 \%$ of the hemithorax) or for patients who developed complications, such as the formation of bronchopleural fistula, pneumothorax, significant atelectasis, superinfection signs, or cardiorespiratory instability by compression. In more serious cases or those refractory to conventional treatments, a surgical approach by thoracoscopy or thoracotomy may be necessary, and although it is extremely rare, some patients even undergo lung segmental resection as definitive treatment ${ }^{4,6,10}$.

\section{Conclusion}

Pulmonary pneumatoceles may develop as a complication of bacterial pneumonia, especially after staphylococcal pneumonia in pediatric patients. However, they are very rarely observed in adults or in association with viral pneumonia. Moreover, pneumatoceles may occur in association with mechanical ventilation or in cases of immunodeficiencies. Although the course is generally asymptomatic and favorable with spontaneous resolution, it may be a serious complication that needs an invasive approach for its treatment.

\section{Funding}

This research has not received any grants from public, commercial or non-profit organization.

\section{Conflicts of interest}

The authors declare no conflicts of interest.

\section{Ethical disclosures}

Protection of human and animal subjects. The authors declare that no experiments were performed on humans or animals for this study. 
Confidentiality of data. The authors declare that they have followed the protocols of their work center on the publication of patient data.

Right to privacy and informed consent. The authors have obtained the written informed consent of the patients or subjects mentioned in the article. The corresponding author is in possession of this document.

\section{References}

1. McGarry T, Giosa R, Rohman M, Huang CT. Pneumatocele formation in adult pneumonia. Chest. 1987;92:717-20.

2. Kunyoshi V, Cataneo DC, Cataneo AJ. Complicated pneumonias with empyema and/or pneumatocele in children. Pediatr Surg Int. 2006;22: $186-90$
3. Al-Ghafri M, Al-Hanshi S, Al-Ismaily S. Two cases of pneumatoceles in mechanically ventilated infants. Oman Med J. 2015;30:299-302.

4. Bajpai J, Kant S, Kumar A, Kumar D. Spontaneous lung pneumatocele in an adult with community-acquired pneumonia. Egypt J Intern Med. 2017;29:141-3.

5. Chateau B, Aravena C, Vuletín F. Neumonía complicada con neumatocele en un lactante: caso clínico. Rev Chil Pediatr. 2008;79:295-300.

6. Gerdung C, Ross BC, Dicken B, Bjornson C. Pneumonectomy in a child with multilobar pneumatocele secondary to necrotizing pneumonia: case report and review of the literature. Case Re in Pediatr. 2019;2019:2464390.

7. Colling J, Allaouchiche B, Floccard B, Pilleul F, Monneuse O, Tissot E. Pneumatocele formation in adult Escherichia coli pneumonia revealed by pneumothorax. J Infect 2005;51:e109-11.

8. Quigley M, Fraser R. Pulmonary pneumatocele: pathology and pathogenesis. AJR. 1988;150:1275-7.

9. Janil A, Kasi A. Pneumatocele. Treasure Island, FL: StatPearls Publishing; 2020. Available from: https://www.ncbi.nlm.nih.gov/books/ NBK556146. [Last accessed on 2020 May 28].

10. Shu-Wing K, Tak-Ching Y. Decompression of multiple tension pneumatoceles in a child using computed tomography-guided percutaneous catheter placement. Can Respir J. 2011;18:e82-5. 